\title{
Effect of dietary conjugated linoleic acid (CLA) and thermal processing on fatty acid composition of enriched chicken meat
}

\author{
M. Franczyk-Żarów', ${ }^{1,3}$ A. Koronowicz'1 , B. Szymczyk² ${ }^{2}$ R. Bieżanowska-Kopeć1 and T. Leszczyńska' \\ ${ }^{1}$ University of Agriculture in Krakow, Faculty of Food Technology, Department of Human Nutrition \\ Balicka 122, 30-149 Kraków, Poland \\ ${ }^{2}$ The National Research Institute of Animal Production, Department of Animal Nutrition and Feed Sciences \\ Krakowska 1, 32-083 Balice, Poland
}

KEY WORDS: conjugated linoleic acid, thermal processing, fatty acid composition, chicken meat

Received: 17 February 2017

Revised: $\quad 28$ April 2017

Accepted: 17 August 2017

${ }^{3}$ Corresponding author:

e-mail: mfranczyk-zarow@ar.krakow.pl

\begin{abstract}
The objective of this study was to evaluate the effect of conjugated linoleic acid (CLA) and thermal processing on chicken meat. The experiment was performed on forty eight 26-week old Isa Brown chickens randomly allocated to two $(0.00 \%$ vs $0.75 \%$ CLA) dietary treatments. Breast muscles and thighs were thermally processed by the cooking techniques: boiling, roasting and frying. The fatty acid composition was determined in both chicken breast and thigh samples. Cooking losses and, consequently, total lipids, increased directly along with following cooking methods: frying > roasting > boiling. Regardless the CLA supplementation, the dry matter and total fat contents were unchanged in raw chicken meat. During processing, the contribution of fatty acids $\left(\mathrm{g} \cdot 100 \mathrm{~g}^{-1}\right.$ of total fatty acids) was changing. Regardless the CLA supplementation, the fatty acid content (mg $100 \mathrm{~g}^{-1}$ meat) was unchanged in raw meat. The amounts of total saturated, monounsaturated and polyunsaturated fatty acids were significantly increased after frying and roasting. Considering the CLA content in the thermally processed meat, it was shown that roasting is the most favourable process, and the amounts of CLA-isomers in thigh were above 3 -fold higher than in breast meat. Thus, CLA-enriched chicken roasted thigh seems to be the valuable source of CLA isomers for humans.
\end{abstract}

\section{Introduction}

Meat and meat products are important sources of protein, essential amino acids, fat, vitamins, minerals and other nutrients. However, consumers in many countries consider meat and meat products as unfavourable for health. In recent years, much attention has been paid to develop nutritional strategies that improve the functional value of meat and meat products (Rozbicka-Wieczorek et al., 2012, 2014; Białek et al., 2017). Generally, people look for healthier meat with reduced level of cholesterol, fat, decreased contents of nitrite and sodium chloride as well as enhanced composition of fatty acid profile (Arihara, 2006) which should have also healthpromoting properties.

One of bioactive compounds of animal origin is conjugated linoleic acid (CLA). CLA, initially classified as an anticancerogenic compound in extracts of grilled beef, is a collective term describing a mixture of geometric and positional isomers of linoleic acid, which have two conjugated double bonds located at positions 7,9-, 8,10-, 9,11-, 10,12- or 11,13- in the fatty acid chain. Among all isomers, the trans-10,cis-12 
and cis-9,trans-11 are the most investigated, but the predominant one is the latter, due to its biological properties (Pariza et al., 2001). Many health-related properties of CLA isomers have been studied including antioxidant, antiobesity, anticancerogenic, antiatherosclerotic, protection of immune system and contribution to bone formation and body composition. There is an extensive literature suggesting that cis-9,trans-11 CLA has anticancer and other positive health properties, while trans-10,cis-12 isomer is thought to be responsible for the reduction in lipid deposition (Pariza et al., 2001). The abilities of dietary CLA to improve meat quality, increase animal performance and provide meat products with high amounts of CLA have also been evaluated. The composition of products of animal origin could be improved by the animal feed. Several studies have shown that in animals, feeding conditions affect the contents of bioactive components, such as CLA in poultry products (Du et al., 2001; Szymczyk et al., 2001; Sirri et al., 2003; Kawahara et al., 2009; Jiang et al., 2014).

The CLA content in pork, chicken and horsemeat is usually lower than $1 \mathrm{mg} \cdot \mathrm{g}^{-1}$ lipid (Schmid et al., 2006). Several factors, such as breed, age and feed composition affect the CLA content in meat (Dhiman et al., 2005). CLA can be incorporated into meat, milk and egg by supplementing animal diets with CLA. However, dietary CLA may affect the sensory characteristics of animal origin foods. Hard-boiled eggs from hens fed CLA-enriched diet were rubberlike, elastic and difficult to break by an Instron (Ahn et al., 1999), whereas the improved marbling of loin and reduced overall fat content were found in meat from CLA-fed pigs (Dugan and Aalhus, 1999).

Poultry meat contains more polyunsaturated fatty acids (PUFA) than red meat. Also it can be more prone to oxidative changes during processing. It was reported that dietary CLA is able to reduce the content of PUFA in meat. Therefore, meat from animals fed CLA will be less susceptible to lipid oxidation, colour changes and volatile production than meat from those fed a control diet. Since chicken meat is not consumed raw, cooking and other processing methods that may alter the original content of CLA in meat also deserve investigation. Cooking allows to achieve a palatable and safe meat product. However, heat treatment can lead to undesirable changes, such as a decrease in the nutritional value, which resulted primarily from mineral and vitamin losses and changes in the fatty acid composition due to lipid oxidation (Rodriguez-Estrada et al., 1997).

Despite the fact that there are several studies focused on the effect of cooking on fatty acid com- position (Badiani et al., 2002; Sarriés et al., 2009; Alfaia et al., 2010), to the best of our knowledge, there is no data concerning the effect of thermal processing on CLA isomeric distribution in chicken meat. Moreover, it is not well known how household thermal processing affect CLA enriched meat. Thus, the objective of this study was to investigate the influence of dietary CLA on fatty acid composition, with special emphasis on the isomeric distribution of the two major cis-9,trans-11 and trans-10,cis-12 CLA isomers, in chicken meat during different common culinary practices (boiling, roasting and frying). In addition, through the use of lipid conversion factors, the study evaluate whether CLA-enriched chicken breasts and thighs that underwent thermal processing are a good source of this bioactive compound for consumers and can be considered as a potential functional food products.

\section{Material and methods}

\section{Animals, housing, diets and experimental design}

All procedures involving animals were approved by the $2^{\text {nd }}$ Local Animal Ethics Commission in Krakow (IF PAN, 12 Smetna, Krakow, Poland).

Forty eight 26-week-old laying hens of Isa Brown strain were housed in individual cages with wiremesh floor in a temperature-controlled environment $\left(22-25^{\circ} \mathrm{C}\right)$ with a $14 / 10 \mathrm{~h}$ light/dark cycle. Animals had free access to water and feed (provided by The National Research Institute of Animal Production, Kraków, Poland). The hens were randomly allocated to control $(0.00 \%$ CLA) or experimental $(0.75 \%$ CLA) group ( $n=24$ in each). The experiment lasting 4 months was preceded by one-week adaptation period. The experimental diets (Table 1) were calculated to provide $2738 \mathrm{kcal} \cdot \mathrm{kg}^{-1}$ and $17 \%$ crude protein. The $0.75 \%$ dietary CLA concentration was formulated using previously determined optimal quantity for nutritional enrichment of eggs (Franczyk-Żarów et al., 2008). The CLA supplement used in this study (TONALIN FFA 80) was supplied by BASF Company (Ludwigshafen, Germany) and contained 80\% CLA glycerides (approx. 80\% triglycerides, 20\% diglycerides and less than $1 \%$ monoglycerides) in 50:50 ratio for cis-9,trans-11 and trans-10,cis-12 isomers. CLA was added to the experimental diet at the expense of sunflower oil. The fatty acid composition of experimental and control diets is presented in Table 2. At the end of the experiment, control and experimental hens were weighted individually, 
Table 1. Composition of experimental diets, $\mathrm{g} \cdot \mathrm{kg}^{-1}$

\begin{tabular}{lcc}
\hline \multirow{2}{*}{ Ingredient } & Diet & \\
\cline { 2 - 3 } & $0.00 \%$ CLA & $0.75 \%$ CLA \\
\hline Wheat middling & 260.0 & 260.0 \\
Ground yellow maize & 350.0 & 350.0 \\
Soyabean meal (45\% CP) & 213.7 & 213.7 \\
Dried grass & 30.0 & 30.0 \\
Rapeseed oil (double 00) & 15.0 & 15.0 \\
CLA $^{1}$ & 0.0 & 9.4 \\
Sunflower oil & 25.0 & 15.6 \\
Calcium carbonate & 81.0 & 81.0 \\
Dicalcium phosphate & 17.0 & 17.0 \\
NaCl & 3.0 & 3.0 \\
Vitamin-mineral premix & 5.0 & 5.0 \\
DL-methionine (99\%) & 0.1 & 0.1 \\
L-lysine $\mathrm{HCl}(80 \%)$ & 0.2 & 0.2 \\
\hline
\end{tabular}

${ }^{1}$ the source of conjugated linoleic acid (CLA) used in this experiment contained $80 \%$ of CLA (TONALIN FFA 80 , BASF, Ludwigshafen, Germany). The dietary treatment consisted of $0.94 \%\left(9.4 \mathrm{~g}^{\prime} \mathrm{kg}^{-1}\right)$ of the commercial CLA. The resulting dietary concentration was $0.75 \%$; ${ }^{2}$ provided per $\mathrm{kg}$ of diet: $\mathrm{mg}$ : vit. A (retinol) 3.6, vit. $\mathrm{D}_{3}$ (cholecalciferol) 0.08125 , vit. E (alpha-tocopherol) 40 , vit. $\mathrm{K}_{3}^{3}$ (menadione) 2.25, mg; vit. $\mathrm{B}_{1}$ (thiamine) 2, vit. $\mathrm{B}_{2}$ (riboflavin) 7.25 , vit. $B_{6}$ (pyridoxine) 4.25 , vit. $B_{12}$ (cyanocobalamin) 0.03 , biotin 0.1 , Ca-pantotenate 12, niacin 40, folic acid 1, choline chloride 450, $\mathrm{Mn}\left(\mathrm{MnSO}_{4}\right)$ 100, Zn ( $\left.\mathrm{ZnO}\right) 65, \mathrm{Fe}\left(\mathrm{FeSO}_{4}\right) 65, \mathrm{Cu}\left(\mathrm{CuSO}_{4}\right)$ 15, I (KI) 0.8, $\mathrm{Se}\left(\mathrm{Na}_{2} \mathrm{SeO}_{3}\right) 0.25$

stunned and slaughtered by neck cutting and bled out. Carcasses were plucked, eviscerated and divided into breasts, thigh muscles and wings. Samples were stored at $-20^{\circ} \mathrm{C}$ until analysis.

\section{Thermal processing of chicken meat}

Frozen breast and thigh muscles were thawed overnight at $4 \pm 2{ }^{\circ} \mathrm{C}$, trimmed of connective and adipose tissues and prepared to cooking treatments

Table 2. Fatty acid profile of experimental diets, $g \cdot 100 \mathrm{~g}^{-1}$ total fatty acids

\begin{tabular}{lllll}
\hline \multirow{2}{*}{ Fatty acid, \% } & \multicolumn{1}{l}{ Diet } & \multirow{2}{*}{ SEM } & \multirow{2}{*}{$P^{\mathrm{A}}$} \\
\cline { 2 - 5 } & $0.00 \%$ CLA & $0.75 \%$ CLA & & \\
\hline Myristic (C14:0) & $\mathrm{ND}$ & $\mathrm{ND}$ & $\mathrm{ND}$ & $\mathrm{NS}$ \\
Palmitic (C16:0) & 15.82 & 15.44 & 0.46 & $\mathrm{NS}$ \\
Palmitoleic (C16:1) & $\mathrm{ND}$ & $\mathrm{ND}$ & $\mathrm{ND}$ & $\mathrm{NS}$ \\
Stearic (C18:0) & 5.06 & 5.00 & 0.19 & $\mathrm{NS}$ \\
Oleic (C18:1) & 39.60 & 42.21 & 0.54 & $\mathrm{NS}$ \\
Linoleic (C18:2, $n-6)$ & 37.11 & 30.58 & 0.69 & $\mathrm{NS}$ \\
Linolenic (C18:3, $n-3)$ & 2.17 & 2.31 & 0.13 & $*$ \\
cis-9,trans-11 CLA & 0.00 & 2.60 & 0.04 & $* * *$ \\
trans-10,cis-12 CLA & 0.00 & 2.52 & 0.06 & $* * *$ \\
Total SFA & 20.88 & 20.44 & 0.65 & $\mathrm{NS}$ \\
Total MUFA & 39.60 & 42.21 & 0.54 & $\mathrm{NS}$ \\
Total PUFA & 39.28 & 38.01 & 0.67 & $\mathrm{NS}$ \\
\hline
\end{tabular}

SFA - saturated fatty acids; MUFA - monounsaturated fatty acids; PUFA - polyunsaturated fatty acids; SEM - standard error of the mean; ND - not detected; ${ }^{A}$ - statistical probability of treatment: NS - not significant $-P>0.05,{ }^{*}-P<0.05,{ }^{* *}-P<0.01,{ }^{* * *}-P<0.001$ (boiling, roasting and frying). Boiling was conducted at about $100{ }^{\circ} \mathrm{C}$ during $40 \mathrm{~min}$ in the stainless steel pots. For roasting meat was placed in the ovenpans and put into the oven at the temperature $200^{\circ} \mathrm{C}$ for $60 \mathrm{~min}$. Deep fat frying was carried in the frying pans using rapeseed oil. The meat was immersed in hot fat for $30 \mathrm{~min}$. After cooking and cooling (30 $\mathrm{min}, 20-22^{\circ} \mathrm{C}$ ), meat was manually wiped with a paper towel to remove visible exudates. Samples were homogenized with rotary homogenizer and kept frozen at $-20{ }^{\circ} \mathrm{C}$ until analysis. Samples of raw and proceeded meat were analysed for dry matter and total fat content. All samples were then lyophilized (Martin Christ Model Alpha 1-4, Osterode am Harz, Germany), weighed and stored at $-20^{\circ} \mathrm{C}$ until fatty acid profile analysis.

\section{Basic composition of chicken breast and thigh samples}

The total dry matter was determined by oven drying method $\left(105^{\circ} \mathrm{C}\right)$ (Fortuna et al., 2003). The total fat content was estimated applying Soxhlet method with Soxtec Avanti's 2050 Auto Extraction Unit (Tecator Foss, Hillerod, Sweden), using petroleum ether as a solvent (AOAC International, 2006).

\section{Chicken breast and thigh fatty acids extraction and methylation}

Lipids of each sample $(1 \mathrm{~g})$ were extracted by modified Folch procedure (Folch et al., 1957). After overnight agitation on the laboratory shaker with chloroform/methanol $(2: 1)$, extracted lipids were filtrated through Whatman \#1 filter paper and mixed with $4 \mathrm{ml}$ of $0.88 \%$ sodium chloride solution. After phase separation, the top layer was completely removed and chloroform layer was then carefully dried under nitrogen. Each sample $(10 \mathrm{mg})$ was then subjected to saponification $\left(20 \mathrm{~min}, 60{ }^{\circ} \mathrm{C}\right)$ with $0.5 \mathrm{M} \mathrm{KOH}$ in methanol. Free fatty acids were then methylated with $14 \%(\mathrm{v} / \mathrm{v}) \mathrm{BF}_{3}$ in methanol $\left(15 \mathrm{~min}, 60^{\circ} \mathrm{C}\right)$. Finally, fatty acid methyl esters (FAME) were extracted with hexane.

\section{Fatty acids composition of experimental diets, chicken breast and thigh samples}

The fatty acid profiles of experimental diets as well as breast and thigh samples were analysed using gas chromatography-mass spectrometry (GC-MS) analyser (Shimadzu GC-MS, Model QP 5050A, Duisburg, Germany). The FAME mixtures were analysed on a gas chromatograph, equipped with SPTM-2560 silica capillary column $(100 \mathrm{~m} \times 25 \mathrm{~mm}$; $25 \mu \mathrm{m}$ film thickness; Supelco Inc., Bellefonte, PA, USA) and a flame ionization detector. The carrier 
gas was helium with flow rate at $1.8 \mathrm{ml} \cdot \mathrm{min}^{-1}$. The injector and detector temperatures were set on $245^{\circ} \mathrm{C}$ with $1 \mu \mathrm{l}$ injection volume. The initial oven temperature was of $60{ }^{\circ} \mathrm{C}$, held for $5 \mathrm{~min}$, then ramped at $15^{\circ} \mathrm{C} \cdot \mathrm{min}^{-1}$ to $180^{\circ} \mathrm{C}$ and held for $16 \mathrm{~min}$, then ramped at $5{ }^{\circ} \mathrm{C} \cdot \min ^{-1}$ to $220^{\circ} \mathrm{C}$ and held for $7 \mathrm{~min}$. The overall analytical programme lasted $60 \mathrm{~min}$. The mass spectrometer operated at the option of ionization electrons (Electron Impact) in the full spectrum scanning: 40 to $500 \mathrm{~m} / \mathrm{z}$. The ionization energy was $70 \mathrm{eV}$. Identification of fatty acid methyl esters was based on the reference mixture of these compounds (FAME Mixture, Larodan Fine Chemicals, Malmö, Sweden) and mass spectra library (NIST 1.7). The profile of fatty acid methyl esters was expressed as $\mathrm{g} \cdot 100 \mathrm{~g}^{-1}$ total fatty acids based on the analytical signal. The analyses were performed in replicates of six.

\section{Calculating fatty acid contents in chicken breast and thigh meat with lipid conversion factors}

In our study the following lipid conversion factors were used: chicken light meat (breast) 0.810 and chicken dark meat (thigh) 0.860 for calculation of total fatty acids (FA) from total lipids (Weihrauch et al., 1977). The fatty acids composition data were shown as: $\mathrm{g} \cdot 100 \mathrm{~g}^{-1}$ total FA and $\mathrm{mg} \cdot 100 \mathrm{~g}^{-1}$ product.

\section{Statistical analysis}

The obtained results were expressed as mean \pm standard deviation (SD). The data were subjected to two-way analysis of variance ANOVA calculated by STATISTICA 10.0 package (StatSoft Inc., Palo Alto, CA, USA). The normality of results and homogeneity of variances were calculated using the Shapiro-Wilk and t-test. Variables with normal distribution and uniform variances were calculated by two-way ANOVA (thermal processing and CLA) and the significance of differences was established using post-hoc Duncan's multiple range test. Values of $P<0.05$ were considered significantly different.

\section{Results}

\section{Effect of dietary CLA and thermal processing on dry matter and total fat content in chicken meat}

Regardless the CLA supplementation, the dry matter content was unchanged in raw chicken breast and thigh meat (Table 3). When different culinary techniques were used the significant changes in dry matter amount have been observed. In boiled and roasted meat the dry matter contents were significantly elevated. Fried chicken meat was marked by the highest content of dry matter compared to raw meat ( 56.79 vs $43.08 \%$ in control breast; 60.66 vs $42.76 \%$ in control thigh; whereas for CLA-enriched group values were as follows: 54.20 vs $43.49 \%$ and 60.97 vs $43.56 \%$ for breast and thigh, respectively).

Considering the fat content (Table 3), regardless the CLA addition, no significant changes have been shown in both raw breast and raw thigh. Additionally, in boiled and roasted breast (from control group) the total fat content was also unchanged. Whereas, control roasted breast had the lowest total fat content $(0.27 \%)$. But in roasted breast meat from CLA group total fat amount was significantly increased (2.13\%). Fried breast meat was characterized by the highest amounts of fat. In fried control breast the content of fat was significantly increased in comparison to raw meat ( 6.19 vs $0.35 \%$, respectively) as well to breast from CLA group (6.19 vs $3.18 \%$, respectively). The same results were obtained for chicken thigh meat. Here, the highest total fat content was observed in fried thigh from CLA group as compared to raw meat ( 7.76 vs $1.67 \%$, respectively). Also for control fried thigh the fat amount was significantly elevated in comparison to raw meat ( $6.60 \mathrm{vs} 1.62 \%$, respectively).

Table 3. Effect of dietary conjugated linoleic acid (CLA) and thermal processing on dry matter and total fat content in chicken breast and thigh meat

\begin{tabular}{|c|c|c|c|c|c|c|c|}
\hline \multirow{3}{*}{ Meat type } & \multicolumn{7}{|c|}{ Type of heat processing } \\
\hline & \multicolumn{2}{|c|}{ without processing - raw } & \multicolumn{2}{|l|}{ boiling } & \multicolumn{2}{|l|}{ roasting } & frying \\
\hline & $0.00 \%$ CLA & $0.75 \%$ CLA & $0.00 \% \mathrm{CLA}$ & $0.75 \%$ CLA & $0.00 \%$ CLA & $0.75 \%$ CLA & $0.00 \%$ CLA $\quad 0.75 \%$ CLA \\
\hline \multicolumn{8}{|l|}{ Breast } \\
\hline dry matter, \% & $43.08 \pm 0.03^{a}$ & $43.49 \pm 0.14^{a}$ & $50.03 \pm 0.47^{b}$ & $50.95 \pm 0.20^{c}$ & $50.59 \pm 0.23^{b c}$ & $49.33 \pm 0.29^{d}$ & $56.79 \pm 0.33^{f} 54.20 \pm 0.50^{e}$ \\
\hline total fat, $\%$ & $0.35 \pm 0.07^{a}$ & $0.34 \pm 0.18^{\mathrm{a}}$ & $0.44 \pm 0.09^{a}$ & $0.66 \pm 0.04^{a}$ & $0.27 \pm 0.04^{a}$ & $2.13 \pm 0.41^{b}$ & $6.19 \pm 0.07^{d} \quad 3.18 \pm 0.18^{c}$ \\
\hline \multicolumn{8}{|l|}{ Thigh } \\
\hline dry matter, $\%$ & $42.76 \pm 0.26^{a}$ & $43.56 \pm 0.54^{a}$ & $51.06 \pm 0.16^{b c}$ & $49.88 \pm 3.65^{b}$ & $52.95 \pm 0.58^{c d}$ & $54.59 \pm 0.27^{d}$ & $60.66 \pm 0.28^{\mathrm{e}} 60.97 \pm 0.51^{\mathrm{e}}$ \\
\hline total fat, $\%$ & $1.62 \pm 0.50^{b}$ & $1.67 \pm 0.86^{b}$ & $2.75 \pm 0.51^{\mathrm{a}}$ & $3.09 \pm 0.13^{a}$ & $3.51 \pm 0.06^{a}$ & $5.74 \pm 0.05^{c}$ & $6.60 \pm 0.43^{c} \quad 7.76 \pm 0.12^{d}$ \\
\hline
\end{tabular}


Table 4. Effect of dietary conjugated linoleic acid (CLA) and thermal processing on fatty acid composition of chicken breast meat, $\mathrm{g} \cdot 100 \mathrm{~g}{ }^{-1}$ total fatty acids

\begin{tabular}{|c|c|c|c|c|c|c|c|c|}
\hline \multirow{3}{*}{$\begin{array}{l}\text { Fatty acid profile, } \\
\mathrm{g} \cdot 100 \mathrm{~g}^{-1} \\
\text { total fatty acids }\end{array}$} & \multicolumn{8}{|c|}{ Type of heat processing of chicken breast meat } \\
\hline & \multicolumn{2}{|c|}{ without processing - raw } & \multicolumn{2}{|l|}{ boiling } & \multicolumn{2}{|l|}{ roasting } & \multicolumn{2}{|l|}{ friying } \\
\hline & $0.00 \%$ CLA & $0.75 \%$ CLA & $0.00 \%$ CLA & $0.75 \%$ CLA & $0.00 \%$ CLA & $0.75 \%$ CLA & $0.00 \%$ CLA & $0.75 \%$ CLA \\
\hline lyristic (C14:0) & $0.98 \pm 0.07^{\mathrm{cd}}$ & $1.04 \pm 0.07^{d}$ & $0.71 \pm 0.05^{a}$ & $0.77 \pm 0.19^{\mathrm{a}}$ & $0.82 \pm 0.34^{\mathrm{ac}}$ & $0.73 \pm 0.08^{\mathrm{a}}$ & $0.18 \pm 0.02^{b}$ & $\quad 0.27 \pm 0.10^{b}$ \\
\hline Palmitic (C16:0) & $27.72 \pm 0.68^{c}$ & $28.18 \pm 0.65^{c}$ & $25.51 \pm 0.77^{\mathrm{ab}}$ & $25.69 \pm 1.28^{\mathrm{ab}}$ & $23.77 \pm 3.03^{\mathrm{a}}$ & $26.99 \pm 0.45^{b c}$ & $9.16 \pm 0.30^{d}$ & d $12.14 \pm 2.97^{\mathrm{e}}$ \\
\hline Palmitoleic (C16:1) & $0.97 \pm 0.12^{2 \mathrm{~b}}$ & $0.80 \pm 0.08^{b}$ & $1.20 \pm 0.10^{\mathrm{ac}}$ & $0.92 \pm 0.21^{\mathrm{ab}}$ & $1.32 \pm 0.37^{c}$ & $1.12 \pm 0.44^{\mathrm{ac}}$ & $0.46 \pm 0.08^{d}$ & ${ }^{d} \quad 0.25 \pm 0.14^{d}$ \\
\hline 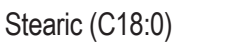 & $13.70 \pm 0.36^{a}$ & $14.16 \pm 0.63^{\mathrm{a}}$ & $12.69 \pm 0.48^{a}$ & $13.02 \pm 1.06^{\mathrm{a}}$ & $12.50 \pm 2.85^{\mathrm{a}}$ & $13.74 \pm 0.71^{\mathrm{a}}$ & $4.62 \pm 0.26^{b}$ & $6.71 \pm 1.63^{c}$ \\
\hline Oleic $(C$ & $28.32 \pm 0.90^{a}$ & $25.49 \pm 0.97^{e}$ & $32.75 \pm 0.62^{\mathrm{cd}}$ & $29.75 \pm 2.54^{\mathrm{ab}}$ & $34.07 \pm 3.96^{d}$ & $27.85 \pm 1.26^{a}$ & $52.82 \pm 1.03^{f}$ & 30.84 \\
\hline Linoleic (C18:2, n-6) & $27.18 \pm 0.24^{a}$ & $27.29 \pm 0.33^{a}$ & $25.79 \pm 0.59^{a b}$ & $24.86 \pm 0.53^{\mathrm{ab}}$ & $26.11 \pm 1.15^{\mathrm{ab}}$ & $25.34 \pm 0.17^{\mathrm{ab}}$ & $23.72 \pm 0.59^{b}$ & $47.99 \pm 5.63^{c}$ \\
\hline Linolenic (C18:3, $n-3)$ & $1.13 \pm 0.11^{\mathrm{ab}}$ & $1.19 \pm 0.07^{\mathrm{ab}}$ & $1.27 \pm 0.42^{\mathrm{a}}$ & $1.86 \pm 0.34^{c}$ & $1.43 \pm 0.30^{\mathrm{a}}$ & $1.39 \pm 0.20^{\mathrm{ac}}$ & $9.04 \pm 0.73^{d}$ & d $\quad 0.76 \pm 0.40^{b}$ \\
\hline cis-9,trans-11 CLA & ND & $1.23 \pm 0.12^{c}$ & ND & $1.89 \pm 0.19^{a}$ & ND & $1.75 \pm 0.26^{a}$ & ND & $0.66 \pm 0.53^{b}$ \\
\hline trans-10, cis-12 CLA & ND & $0.65 \pm 0.06^{c}$ & ND & $1.24 \pm 0.19^{a}$ & ND & $1.12 \pm 0.08^{\mathrm{a}}$ & ND & $0.39 \pm 0.38^{b}$ \\
\hline Total SFA & $42.40 \pm 0.95^{\mathrm{cd}}$ & $43.37 \pm 1.07^{d}$ & $38.90 \pm 1.21^{\mathrm{ab}}$ & $39.48 \pm 2.00^{\mathrm{abc}}$ & $37.08 \pm 5.43^{\mathrm{a}}$ & $41.46 \pm 1.11^{\mathrm{bcd}}$ & $13.96 \pm 0.39 \mathrm{e}$ & $19.12 \pm 4.67^{f}$ \\
\hline Total MUFA & $29.30 \pm 0.89^{a}$ & $26.29 \pm 1.02^{c}$ & $33.94 \pm 0.58^{b}$ & $30.67 \pm 2.47^{\mathrm{a}}$ & $35.39 \pm 4.28^{b}$ & $28.97 \pm 0.95^{a}$ & $53.28 \pm 0.98^{d}$ & d $31.08 \pm 0.84^{a}$ \\
\hline Total PUFA & $28.31 \pm 0.16^{a b c}$ & ${ }^{c} 30.34 \pm 0.34^{a}$ & $27.06 \pm 0.82^{b}$ & $29.85 \pm 0.56^{\mathrm{a}}$ & $27.53 \pm 1.39^{\mathrm{bc}}$ & ${ }^{c} 29.59 \pm 0.59^{\mathrm{ac}}$ & $32.76 \pm 1.11^{\mathrm{d}}$ & $49.80 \pm 4.38^{\mathrm{e}}$ \\
\hline
\end{tabular}

a-f - means with different superscripts within the same row are significantly different at $P<0.05$; results are presented as mean \pm standard deviation (SD); ND - not detected; the analyses were performed in replicates of six

\section{Effect of dietary CLA and thermal processing on fatty acid composition of chicken meat}

The most significant changes in fatty acid profile ( $\mathrm{g} \cdot 100 \mathrm{~g}^{-1}$ of total FA) of breast meat have been shown for frying (Table 4). Saturated fatty acids (SFA) contribution was significantly decreased in fried samples, mainly through decreasing myristic (C14:0), palmitic (C16:0) and stearic (C18:0) acids. Whereas, monounsaturated fatty acids (MUFA) participation was significantly increased, mainly through increased oleic (C18:1) acid content. The same results were obtained for PUFA, due to increased contribution of linoleic $(\mathrm{C} 18: 2, n-6)$ and linolenic $(\mathrm{C} 18: 3, n-3)$ acids. These changes were caused mainly by the quantitative addition of rapeseed oil to frying. Similar changes have been observed for chicken thigh meat (Table 5).

During heat processing, especially frying, contribution of fatty acids ( $\mathrm{g} \cdot 100 \mathrm{~g}^{-1}$ of total FA) was changing. Therefore, in order to determine the quantitative real changes among fatty acids during thermal processing, the lipid conversion factors were used. From a nutritional point of view and consumer convenience, the quantitative fatty acids composition, expressed as $\mathrm{mg} \cdot 100 \mathrm{~g}^{-1}$ meat, was determined in both chicken breast and thigh samples (Tables 6 and 7).

Regardless the CLA supplementation, the fatty acid content was unchanged in raw chicken meat. When fatty acid profile of breast meat is considered, the most significant changes have been shown for roasting and frying. In contrast to fatty acid profile expressed as $\mathrm{g} \cdot 100 \mathrm{~g}^{-1}$ of total FA, significantly increased amount of total SFA (mg $\cdot 100 \mathrm{~g}^{-1}$ meat) was observed, especially in roasted breast from CLA group and in control fried breast as compared to raw meat (715.34 and $700.02 \mathrm{mg} \cdot 100 \mathrm{~g}^{-1}$ vs 119.45 and $120.19 \mathrm{mg} \cdot 100 \mathrm{~g}^{-1}$, respectively). This dramatic increase was caused mainly through increased myristic (C14:0), palmitic (C16:0) and stearic (C18:0) acids content. The same results were obtained for MUFA. Increased oleic (C18:1) acid content, especially in fried control breast in comparison to raw meat $\left(2648.34 \mathrm{vs} 80.30 \mathrm{mg} \cdot 100 \mathrm{~g}^{-1}\right)$, caused significant elevated amount of total MUFA (2671.41 vs $83.06 \mathrm{mg} \cdot 100 \mathrm{~g}^{-1}$ ). Also, the total content of PUFA was significantly increased in roasted and fried breast from CLA group in comparison to raw meat. However, the highest increase was found in control fried breast, mainly through elevated levels of linoleic $(\mathrm{C} 18: 2, n-6)$ and linolenic $(\mathrm{C} 18: 3, n-3)$ acids. Here, total PUFA content was $1642.47 \mathrm{mg} \cdot 100 \mathrm{~g}^{-1}$ in comparison to raw sample $80.25 \mathrm{mg} \cdot 100 \mathrm{~g}^{-1}$.

Similarly, in chicken thigh fatty acid composition the same trends: increased SFA, MUFA and PUFA in total fatty acid contents were noted.

\section{Effect of dietary CLA and thermal processing on CLA concentration of chicken meat}

In group in which CLA oil was provided, cis-9, trans-10 isomer was incorporated predominantly. 

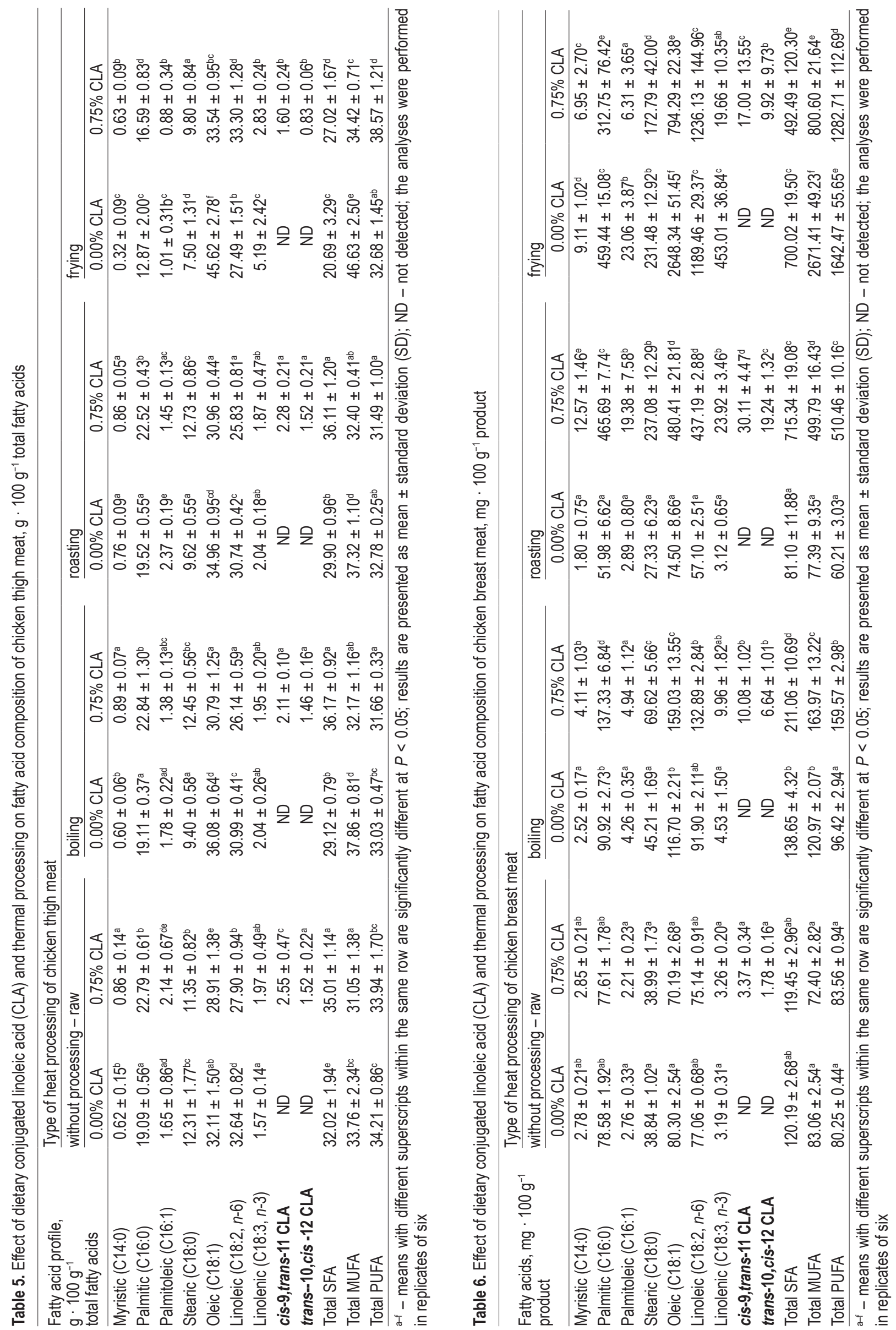


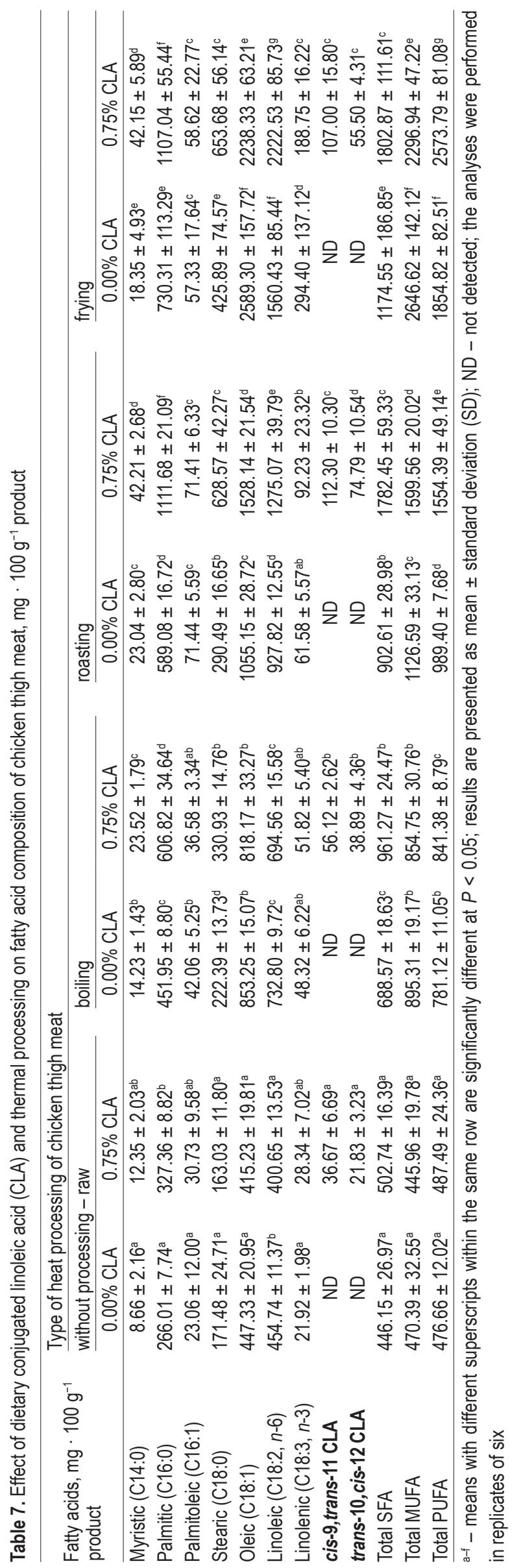

The highest content of both CLA isomers $\left(\mathrm{g} \cdot 100 \mathrm{~g}^{-1}\right.$ of total FA) was in boiled chicken breast and in raw chicken thigh.

Considering the contents of CLA isomers (mg $\cdot 100 \mathrm{~g}^{-1}$ product), it was shown that the highest amount was incorporated in roasted chicken breast in comparison to raw meat: $30.11 \mathrm{vs} 3.37 \mathrm{mg} \cdot 100 \mathrm{~g}^{-1}$ for cis-9, trans-11 CLA and 19.24 vs $1.78 \mathrm{mg} \cdot 100 \mathrm{~g}^{-1}$ for trans-10, cis-12 CLA. Also, the preferential incorporation of cis-9,trans-11 CLA has been confirmed. Taking into account the CLA incorporation in thigh samples, it was observed that the highest amount was incorporated in roasted chicken thigh as compared to raw meat: $112.30 \mathrm{vs} 36.67 \mathrm{mg} \cdot 100 \mathrm{~g}^{-1}$ for cis-9,trans-11 CLA and 74.79 vs $21.83 \mathrm{mg} \cdot 100 \mathrm{~g}^{-1}$ for trans-10,cis-12 CLA. Moreover, these values were higher than in chicken breast.

\section{Discussion}

Meat composition, as well as its physicochemical properties, undergo significant changes during heat treatment. A specific cooking technique together with fat content are among the factors that mostly affect the final quality of meat products (Serrano et al., 2007). The cooking process changes the nutritional value of cooked products in comparison to raw meat, because it affects the lipid composition of meat, mainly fatty acid content (Badiani et al., 2002). Additionally, heat treatment can lead to undesirable changes, such as a loss of essential fatty acids that, mainly due to lipid oxidation, reduce the nutritional value of meat (Rodriguez-Estrada et al., 1997). However, there is a great variableness of changes concerning individual fatty acids in relation to different cooking techniques (Badiani et al., 2002).

The thermal processing methods, which would preserve nutritional value of meat, are sought and investigated. For example, Sarriés et al. (2009) recommended cooking loosely capped (to prevent pressure build up and to minimize evaporation) beef $\left(140{ }^{\circ} \mathrm{C}\right.$ for $\left.30 \mathrm{~min}\right)$ in oven in glass bottles arounded with aluminium foil (to eliminate light). This procedure does not cause detrimental changes in the nature or content of the fatty acids in meat. So, it can be recommended to preserve the nutritional value of meat (Sarriés et al., 2009). However, this method does not reflect the ordinary cooking practices in households.

The three different meat cooking methods (boiling, roasting and frying) used in this study, differed in the processing parameters (temperature and 
cooking time). These conditions were chosen as the most popular in heat processing of chicken meat in order to obtain the chicken portion size (200 g), according to Szponar et al. (2000). The cooking losses were affected by the cooking method used. The losses depend on the mass transfer process during thermal treatment, which is directly connected with the cooking procedure (temperature, time, medium - water, oil, etc.) and with the properties of raw meat (moisture, size, etc.) (Serrano et al., 2007).

Effect of dietary CLA and thermal processing on dry matter and total fat content in chicken meat. It was shown that cooking losses were the greatest during frying, where a lot of moisture had been lost by evaporation. In comparison to the raw meat, cooking methods led to a significant loss of moisture (increased dry matter), and consequently, to a significantly higher fat content, with significant differences among treatments (frying $>$ roasting $>$ boiling). Increased concentration of most nutrients was a consequence of moisture loss through cooking (Badiani et al., 2002). Significant losses were more evident after frying, which induced a considerable decrease in moisture level, e.g., $17.9 \%$ in control chicken thigh or $13.71 \%$ in control chicken breast meat. Whereas, lower losses of moisture were observed for fried meat from CLA-enriched group: $17.41 \%$ for thigh and $10.71 \%$ for breast meat. The total fat contents obtained in this study $(0.35 \%$ for raw control breast and $6.19 \%$ for fried control breast) were generally lower than those reported in literature (e.g., Badiani et al., 2002). However, our results confirm that fat content increases as total moisture content decreases. Similarly, in the study of Juárez et al. (2010) common ways of cooking (frying, boiling and grilling) caused reduced moisture and increased fat and protein content in buffalo meat. As expected, thermal processing induces water loss in meat. Loss of the water results probably from heat-induced denaturation of proteins during cooking. Thus, higher water loss (moisture decrease, dry matter increase) determined higher increases in other components. Therefore, frying lead to the highest moisture decrease, followed by roasting. The lowest water loss was found during boiling due to the incorporation of water into the meat during cooking. In contrast, the increase in fat content was higher after frying not only due to the water loss but also due to the incorporation of fat from rapeseed oil. The incorporation of rapeseed oil to fried meat samples was confirmed by increasing oleic acid (18:1) as well as linolenic acid $(18: 3, n-3)$ contents, which are the main fatty acids present in rapeseed oil (Orsavova et al., 2015).
Effect of dietary CLA and thermal processing on fatty acid composition of chicken meat. In the present study it was demonstrated that all used cooking methods had an impact on the fatty acids profile ( $\mathrm{g} \cdot 100 \mathrm{~g}^{-1}$ of total FA) of chicken meat. Differences in the fatty acid profile of raw and cooked samples have already been found by Echarte et al. (2003), who observed significant variations in the fatty acid composition of both beef and chicken patties. The same was true for buffalo meat composition affected by boiling, grilling and frying studied by Juárez et al. (2010). Also, Alfaia et al. (2010) showed how the cooking techniques affect fatty acids content, conjugated isomers of linoleic acid presence and nutritional quality of beef intramuscular fat. Several changes during cooking, such as water loss, diffusion and exchange of fatty acids, lipid oxidation, can lead to relative changes in the composition of FA (RodriguezEstrada et al., 1997).

Researchers usually report fatty acid data in terms of weight percent of total methyl esters (FAME). However, customers prefer values in $g$ fatty acids per $100 \mathrm{~g}$ of food. Therefore, conversion factors, defined as the weight of fatty acid in $1 \mathrm{~g}$ of the total fat, were obtained for different food products (Weihrauch et al., 1977). The fatty acids composition of chicken tissues reflects the fatty acids composition of the dietary fat. The fatty acids composition data for light meat, dark meat or skin of all classes of chickens and the respective conversion factors are known. Therefore, from a nutritional point of view, the quantitative FA composition (expressed as $\mathrm{mg} \cdot 100 \mathrm{~g}^{-1}$ product) was determined in both raw and cooked chicken. As expected, cooking produced significant increases in FA contents (SFA, MUFA, PUFA). In general, roasting and frying, which likely resulted from the higher moisture loss, led to higher contents of FA in comparison to boiling. As it has been observed the quantitative fatty acids composition is different, particularly in relation to SFA, from the fatty acids profile expressed as $\mathrm{g} \cdot 100 \mathrm{~g}^{-1}$ of total FA. Therefore, the application of lipid conversion factors appears to be reasonable and useful. These results, in particular regarding the total SFA, are similar to other studies considering the CLA supplementation in broiler diets (Szymczyk et al., 2001; Sirri et al., 2003). The increased content of SFA, while decreased content of MUFA and non-CLA PUFA (\%) were reported in other studies (Sirri et al., 2003; Narciso-Gaytán et al., 2011). Moreover, in the study of Cho et al. (2013) it was showed that CLA feeding in overall can increase total SFA concentration in broilers and that the total UFA concentration was significantly decreased 
by CLA feeding. It is supposed that these changes are due to the inhibition of $\Delta 9$-desaturase activity in liver and consequent impaired conversion of C18:0 to C18:1 (Szymczyk et al., 2001). However, these studies reported the effect of one factor, namely CLA, not thermal processing.

The influence of dietary CLA on colour, volatile profiles and lipid oxidation of irradiated raw chicken meat was investigated by Du et al. (2000). The authors observed that dietary CLA reduced the degree of lipid oxidation in raw chicken meat during storage, moreover CLA treatment improved the colour stability of chicken patties. The increased storage stability of CLA enriched cooked meat was also confirmed by Du et al. (2001) in their next study. The authors reported that it was caused by the increased SFA and CLA contents in meat lipids. They also observed that total MUFA and total non-CLA PUFA content decreased with the simultaneous increase of dietary CLA content. Moreover, the CLA isomers itself did not act as an antioxidant. Conjugated structure of linoleic acid made the fatty acid less susceptible to free radical attacks (Du et al., 2000). Additionally, CLA would behave like MUFA and reduce lipid oxidation by minimizing the initiation step of lipid oxidation (Du et al., 2001; Kawahara et al., 2009).

Jiang et al. (2014) confirmed that dietary supplementation with $1 \%$ CLA had positive effects on meat quality, antioxidant capacity and fatty acid composition of broilers. Therefore, in the present study, in order to avoid adverse effects on the quality of chicken meat, the $0.75 \%$ addition of CLA has been selected.

Effect of dietary CLA and thermal processing on CLA concentration of chicken meat. Meat and meat products constitute about $25-30 \%$ of the total human CLA intake in Western populations. This intake could be increased by consumption of CLA containing foodstuffs as well as by meat enhancement with CLA by new animal feeding strategies (Schmid et al., 2006).

In the present study, the total content of the health promoting CLA isomers in cooked breast meat was significantly higher than in raw meat as a result of moisture loss. The greatest content in roasted chicken breast was 9-fold higher than in raw meat. Simultaneously, the greatest content in roasted chicken thigh was 3-fold higher than in raw meat. Moreover, an important finding of this study was that the amounts of CLA-isomers in thigh were above 3-fold higher than in breast meat.

In previous studies higher values of CLA in cooked meat, e.g., beef when compared to uncooked ground beef were also reported (Alfaia et al., 2010).
Regardless of the cooking process, the heating methods with higher internal temperatures had the highest CLA concentrations, mainly due to higher cooking losses. Other studies (Shantha et al., 1994; Sarriés et al., 2009) also showed that CLA is not increased by cooking, but rather by water loss. What is more, CLA is stable and not destroyed by cooking or storage (Sarriés et al., 2009). Dhiman et al. (2005) also confirmed that CLA in milk or meat was stable compound under normal cooking and storage conditions. The CLA isomeric profile showed a clear predominance of the bioactive cis-9,trans-11 isomer in all experimental treatments (Kawahara et al., 2009). No changes were identified after beef cooking in the relative proportions of the bioactive cis-9,trans-11 isomer, likewise, trans-10,cis-12, was not influenced by heating treatments (Alfaia et al., 2010). In conclusion, research indicates that neither cooking nor storing negatively alters the CLA content in meat (Schmid et al., 2006).

The average total CLA intakes assessed so far range between 95 and $440 \mathrm{mg}$ and are different in many countries due to different food patterns and variable CLA contents in food (Schmid et al., 2006). Ritzenthaler et al. (2001) reported that the daily intake of CLA in humans is approximately: $212 \mathrm{mg}$ in man and $151 \mathrm{mg}$ in woman in the USA, the latter being $60 \%$ originated from dairy products and $37 \%$ from meat. It was hypothesized that $95 \mathrm{mg}$ CLA per day is enough to excert positive effects in reducing breast cancer in woman. These estimations were based on epidemiological data linking reduced breast cancer with increased milk consumption (Knekt et al., 1996). Optimal dietary intake should be determined.

In the context of our results, it can be theoretically calculated that the average serving (about $200 \mathrm{~g}$ ) of roasted chicken meat provides $98.7 \mathrm{mg} \mathrm{CLA} / 200 \mathrm{~g}$ of chicken breast or $374.2 \mathrm{mg}$ CLA/200 $\mathrm{g}$ of chicken thigh. Moreover, if we assume that the minimal required amount of CLA for human is $1.5 \mathrm{~g} \cdot \mathrm{d}^{-1}$ (Decker, 1995), the $200 \mathrm{~g}$ of roasted chicken thigh, contribute about $25 \%$ of the total human CLA intake. As we stressed above, our finding is in the line with that of Schmid et al. (2006). However, it is important to note that one portion of chicken meat a day $(200 \mathrm{~g})$ with the levels of CLA achieved in this study, would not be sufficient to fulfil dietary requirements of CLA.

\section{Conclusions}

Chicken meat is susceptible to dietary modification of fatty acids composition and conjugated linoleic acid (CLA) enrichment. However, the CLA addition into hen diet causes higher CLA content in 
chicken thigh than breast. All studied household cooking techniques (boiling, roasting and frying) seem to affect the fatty acids composition. Total CLA content seems to be higher in cooked chicken meat than in raw meat, as a result of the moisture loss and, thus, fat increase. Considering the CLA content in the culinary processed meat, it has been shown that roasting is the most favourable process. Thus, chicken roasted thigh from hens fed diet with $0.75 \%$ CLA content seems to be the valuable source of CLA isomers in human diet.

\section{Acknowledgement}

This work was supported by The Polish National Science Centre (Grant No. 2011/03/B/NZ9/01423) 'Conjugated linoleic acid (CLA)-induced transcriptional activation of PPAR - an investigation of molecular mechanisms of putative anticancer action of fatty acids of CLA-enriched egg yolks'.

\section{References}

Ahn D.U., Sell J.L., Jo C., Chamruspollert M., Jeffrey M., 1999. Effect of dietary conjugated linoleic acid on the quality characteristics of chicken eggs during refrigerated storage. Poult. Sci. 78, 922928, https://doi.org/10.1093/ps/78.6.922

Alfaia C.M.M., Alves S.P., Lopes A.F., Fernandes M.J.E., Costa A.S.H., Fontes C.M.G.A., Castro M.L.F., Bessa R.J., Prates J.A.M., 2010. Effect of cooking methods on fatty acids, conjugated isomers of linoleic acid and nutritional quality of beef intramuscular fat. Meat Sci. 84, 769-777, https://doi.org/10.1016/j.meatsci.2009.11.014

AOAC International, 2006. Official Methods of Analysis of AOAC International. 18 ${ }^{\text {th }}$ Edition. Gaithersburg, MD (USA)

Arihara K., 2006. Strategies for designing novel functional meat products. Meat Sci. 74, 219-229, https://doi.org/10.1016/j.meatsci.2006.04.028

Badiani A., Stipa S., Bitossi F., Gatta P.P., Vignola G., Chizzolini R., 2002. Lipid composition, retention and oxidation in fresh and completely trimmed beef muscles as affected by common culinary practices. Meat Sci. 60, 169-186, https://doi.org/10.1016/ S0309-1740(01)00119-X

Białek A., Czerwonka M., Białek M., Lepionka T., Kaszperuk K., Banaszkiewicz T., Tokarz A., 2017. Influence of pomegranate seed oil and grape seed oil on cholesterol content and fatty acid profile in livers of chickens. Acta Pol. Pharma. - Drug Res. 74, 624-632

Cho S., Ryu C., Yang J., Mbiriri D.T., Choi C.-W., Chae J.-I., Kim Y.-H., Shim K.-S., Kim Y.J., Choi N.-J., 2013. Effect of conjugated linoleic acid feeding on the growth performance and meat fatty acid profiles in broiler: meta-analysis. Asian-Australas. J. Anim. Sci. 26, 995-1002, https://doi.org/10.5713/ajas.2013.13071

Decker E.A., 1995. The role of phenolics, conjugated linoleic acid, carnosine, and pyrroloquinoline quinone as nonessential dietary antioxidants. Nutr. Rev. 53, 49-58, https://doi. org/10.1111/j.1753-4887.1995.tb01502.x

Dhiman T.R., Nam S.-H., Ure A.L., 2005. Factors affecting conjugated linoleic acid content in milk and meat. Crit. Rev. Food Sci. Nutr. 45, 463-482, https://doi.org/10.1080/10408390591034463
Du M., Ahn D.U., Nam K.C., Sell J.L., 2000. Influence of dietary conjugated linoleic acid on volatile profiles, color and lipid oxidation of irradiated raw chicken meat. Meat Sci. 56, 387-395, https://doi.org/10.1016/S0309-1740(00)00067-X

Du M., Ahn D.U., Nam K.C., Sell J.L., 2001. Volatile profiles and lipid oxidation of irradiated cooked chicken meat from laying hens fed diets containing conjugated linoleic acid. Poult. Sci. 80, 235-241, https://doi.org/10.1093/ps/80.2.235

Dugan M.E.R., Aalhus J.L., 1999. Feeding CLA to pigs: effects on feed conversion, carcass composition, meat quality and palatability. In: M.P. Yurawecz, M.M. Mossoba, J.K.G. Kramer, M.W. Pariza, G. Nelson (Editors). Advances in Conjugated Linoleic Acid Research. AOCS Press. Champaign, IL (USA), pp. 354-368

Echarte M., Ansorena D., Astiasarán I., 2003. Consequences of microwave heating and frying on the lipid fraction of chicken and beef patties. J. Agric. Food Chem. 51, 5941-5945, https://doi.org/10.1021/jf0345245

Folch J., Less M., Sloane Stanley G.H., 1957. A simple method for the isolation and purification of total lipids from animal tissues. J. Biol. Chem. 226, 497-509

Fortuna T., Juszczak L., Sobolewska-Zielińska J., 2003. Basic of Food Analyses (in Polish). Wydawnictwo Akademii Rolniczej w Krakowie. Krakow (PL)

Franczyk-Żarów M., Kostogrys R.B., Szymczyk B., Jawień J., GajdaM., Cichocki T., Wojnar L., Chlopicki S., Pisulewski P.M., 2008. Functional effects of eggs, naturally enriched with conjugated linoleic acid, on the blood lipid profile, development of atherosclerosis and composition of atherosclerotic plaque in apolipoprotein $E$ and low-density lipoprotein receptor doubleknockout mice (apoE/LDLR'-1). Br. J. Nutr. 99, 49-58, https:// doi.org/10.1017/S0007114507793893

Jiang W., Nie S., Qu Z., Bi C., Shan A., 2014. The effects of conjugated linoleic acid on growth performance, carcass traits, meat quality, antioxidant capacity, and fatty acid composition of broilers fed corn dried distillers grains with solubles. Poult. Sci. 93, 1202-1210, https://doi.org/10.3382/ps.2013-03683

Juárez M., Failla S., Ficco A., Peña F., Avilés C., Polvillo O., 2010. Buffalo meat composition as affected by different cooking methods. Food Bioprod. Process. 88, 145-148, https://doi. org/10.1016/j.fbp.2009.05.001

Kawahara S., Takenoyama S.-i., Takuma K., Muguruma M., Yamauchi K., 2009. Effects of dietary supplementation with conjugated linoleic acid on fatty acid composition and lipid oxidation in chicken breast meat. Anim. Sci. J. 80, 468-474, https://doi. org/10.1111/j.1740-0929.2009.00658.x

Knekt P., Järvinen R., Seppänen R., Pukkala E., Aromaa A., 1996. Intake of dairy products and the risk of breast cancer. $\mathrm{Br}$. J. Cancer 73, 687-691, https://doi.org/10.1038/bjc.1996.119

Narciso-Gaytán C., Shin D., Sams A.R., Keeton J.T., Miller R.K., Smith S.B., Sánchez-Plata M.X., 2011. Lipid oxidation stability of omega-3- and conjugated linoleic acid-enriched sous vide chicken meat. Poult. Sci. 90, 473-480, https://doi. org/10.3382/ps.2010-01002

Orsavova J., Misurcova L., Ambrozova J.V., Vicha R., Mlcek J., 2015. Fatty acids composition of vegetable oils and its contribution to dietary energy intake and dependence of cardiovascular mortality on dietary intake of fatty acids. Int. J. Mol. Sci. 16, 12871-12890, https://doi.org/10.3390/ijms160612871

Pariza M.W., Park Y., Cook M.E., 2001. The biologically active isomers of conjugated linoleic acid. Prog. Lipid Res. 40, 283298, https://doi.org/10.1016/S0163-7827(01)00008-X 
Ritzenthaler K.L., McGuire M.K., Falen R., Shultz T.D., Dasgupta N., McGuire M.A., 2001. Estimation of conjugated linoleic acid intake by written dietary assessment methodologies underestimates actual intake evaluated by food duplicate methodology. J. Nutr. 131, 1548-1554

Rodriguez-Estrada M.T., Penazzi G., Caboni M.F., Bertacco G., Lercker G., 1997. Effect of different cooking methods on some lipid and protein components of hamburgers. Meat Sci. 45, 365-375, https://doi.org/10.1016/S0309-1740(96)00123-4

Rozbicka-Wieczorek A.J., Szarpak E., Brzóska F., Śliwiński B., Kowalczyk J., Czauderna M., 2012. Dietary lycopenes, selenium compounds and fish oil affect the profile of fatty acids and oxidative stress in chicken breast muscle. J. Anim. Feed Sci. 21, 705-724, https://doi.org/10.22358/jafs/66143/2012

Rozbicka-Wieczorek A.J., Więsyk E., Brzóska F., Śliwiński B., Kowalczyk J., Czauderna M., 2014. Fatty acid profile and oxidative stress of thigh muscles in chickens fed the ration enriched in lycopene, selenium compounds or fish oil. Ann. Anim. Sci. 14, 595-609, https://doi.org/10.2478/aoas-20140041

Sarriés M.V., Murray B.E., Moloney A.P., Troy D., Beriain M.J., 2009. The effect of cooking on the fatty acid composition of longissimus muscle from beef heifers fed rations designed to increase the concentration of conjugated linoleic acid in tissue. Meat Sci. 81, 307-312, https://doi.org/10.1016/j.meatsci.2008.08.006

Schmid A., Collomb M., Sieber R., Bee G., 2006. Conjugated linoleic acid in meat and meat products: A review. Meat Sci. 73, 2941, https://doi.org/10.1016/j.meatsci.2005.10.010
Serrano A., Librelotto J., Cofrades S., Sánchez-Muniz F.J., JiménezColmenero F., 2007. Composition and physicochemical characteristics of restructured beef steaks containing walnuts as affected by cooking method. Meat Sci. 77, 304-313, https:// doi.org/10.1016/j.meatsci.2007.03.017

Shantha N.C., Crum A.D., Decker E.A., 1994. Evaluation of conjugated linoleic acid concentrations in cooked beef. J. Agric. Food Chem. 42, 1757-1760, https://doi.org/10.1021/jf00044a035

Sirri F., Tallarico N., Meluzzi A., Franchini A., 2003. Fatty acid composition and productive traits of broiler fed diets containing conjugated linoleic acid. Poult. Sci. 82, 1356-1361, https:// doi.org/10.1093/ps/82.8.1356

Szponar L., Wolnicka K., Rychlik E., 2000. Album of Photographs of Food Products and Dishes. National Food and Nutrition Institute. Warsaw $(\mathrm{PL})$

Szymczyk B., Pisulewski P.M., Szczurek W., Hanczakowski P., 2001. Effects of conjugated linoleic acid on growth performance, feed conversion efficiency, and subsequent carcass quality in broiler chickens. Br. J. Nutr. 85, 465-473, https://doi. org/10.1079/BJN2000293

Weihrauch J.L., Posati L.P., Anderson B.A., Exler J., 1977. Lipid conversion factors for calculating fatty acid contents of foods. J. Am. Oil Chem. Soc. 54, 36-40, https://doi.org/10.1007/ BF02671370 